\title{
The Location of Appliances Garbage Recycle Bin Based on AHP
}

\author{
Chen Jiao ${ }^{1, \mathrm{a}}$,Wu Yue ${ }^{2, \mathrm{~b}}$,Liang Lei ${ }^{3, \mathrm{c}}$ \\ ${ }^{1}$ Graduate faculty, Beijing Wuzi University, Beijing, 101149, China \\ ${ }^{2}$ Institute for Industrial \\ Research,Beijing Wuzi University, Beijing, 101149, China \\ ${ }^{3}$ Graduate faculty, Beijing Wuzi University, Beijing, 101149, China \\ aemail:18401600408@163.com, ${ }^{b}$ email: \\ 13001230105@wo.com.cn, cemail:764890010@qq.com
}

\begin{abstract}
Appliances garbage not only has a lot of harmful substances, but also has a high economic value of precious metals gold, silver, copper, etc. It can be recycled to reduce pollution and achieve recycling of resources. TV sets, refrigerators, mobile phones and other electronic products also contain lead, chromium, mercury and other heavy metals. If the scrap electronic waste directly landfilled, lead and other heavy metals will penetrate the soil and water.By cycling of the plants, animals , people and food chain, ultimately result in poisoning incidents; if burned, it will release a lot of harmful gases (such as Freon), toxic gases (such as dioxins), seriously harm to human health. Beijing as a large producer of Appliances garbage, to establish a appliances garbage recycle bin is very important.
\end{abstract}

Key words: Appliances Garbage; Recycle Bin Location, AHP

\section{Appliances garbage Status Analysis}

With the new products to replace old equipment, or, or become waste. The sales figures and discard mode based on the number of electronic waste, several publications on the domestic produced estimate[1] .

As old equipment continue to be replaced new products, the obsolete products are temporarily or become waste. Based on domestic sales data and drop mode, several papers publications estimate the number of electronic waste. 
The following table lists the overview of these different reference estimator in the year of 2013.

Table.1. Estimators of 2012

\begin{tabular}{|l|l|l|l|l|l|}
\hline References & TV & Fridge & $\begin{array}{l}\text { Washing } \\
\text { Machine }\end{array}$ & Air-conditioning & Computer \\
\hline $\begin{array}{l}\text { 1. Li Jinhui etc. } \\
\text { (2005, 2006) } \\
\text { [9-11] }\end{array}$ & 32.5 & 9.7 & 12.8 & 36.7 & 107.9 \\
\hline $\begin{array}{l}\text { 2.Tian Hui } \\
\text { (2012) [12] }\end{array}$ & 27.5 & 7.6 & 12.1 & 15.4 & 69.5 \\
\hline $\begin{array}{l}\text { 3. Yang Jianxin } \\
\text { etc. } \\
\text { (2008) [13] }\end{array}$ & 60.2 & 12.1 & 13.3 & 6.6 & 22.7 \\
\hline \begin{tabular}{l} 
Average[milion] \\
\hline $\begin{array}{l}\text { Average } \\
\text { weight[kg/ } \\
\text { Piec] }\end{array}$
\end{tabular} 30 & 9.8 & 45 & 25 & 51 & 15 \\
\hline $\begin{array}{l}\text { Total } \\
\text { weight[Million } \\
\text { tons] }\end{array}$ & 1.2 & 0.44 & 0.32 & 0.99 & 0.67 \\
\hline
\end{tabular}

Four references indicated that, forecasting result is different among the product scope, the method and the parameter. [2]The main difference lies in the market sale data and the product life probability distribution origin. The estimate obsolete quantity of refrigerator and the washer has the suitable uniformity in these references.There are 9.8 million towers and 12.7 million towers in 2013. The number of obsolete television is between 22.7 million towers and 60.02 million towers. The air conditioning is between 6.6 million towers and 3.67 million towers. For computers, The estimate number is based on whether containing notebook computers . In 2012, the amount of generated waste computer is 66.7 million towers.The total weight of waste appliances can be obtained by multiplying the total number and the weight of units . It is estimated 
that in 2012 there are 1.2 million tons TV, 0.44 million tons refrigerators, 0.32 million tons washing machines, 0.99 million tons and 0.67 million tons computer is eliminated. Overall, these five waste products totaled 3.62 million tons;Since 2011, this number has been steadily on the increase. In addition, parameters and range selection method for estimation of the different, result in differences estimation results of the great. So in 2012,it need to furtherly validate the results through the unified data source and using a consistent estimation method .

\section{Analysis of appliance waste problems}

At present, Beijing have no well-known home appliance waste and recycling second-hand home appliances products supermarket or site. Beijing city waste home appliances, the vast majority of the terminal is used as mobile phone, MP3, computer, through low-cost recovery ways of informal, modified or upgraded, again sold to consumers, other worthless parts directly as ordinary garbage disposal. And the number of household electrical appliances recycling to few to get most of the lack of effective recycling. The recovery of profits from reselling the individual phenomenon mainly concentrated in Zhongguancun and Muxiyuan, Gongzhufen region. This is a serious violation of the legitimate rights and interests of consumers, so that household electrical appliances market is very chaotic, bad environment. ${ }^{[3]}$

The main reasons are the following:

(1) The national resources and environmental protection consciousness are backward.

(2) The incentive mechanism and policy of resource recycling regeneration are not effective.

(3) Recycling of appliances waste product is difficult.

(4) The location recycling bin are not reasonable and the number is few.

(5) Everywhere is illegal recycling appliances products 


\section{The AHP model analysis}

\subsection{The influence factors of the appliances garbage recycle bin location}

(1)Convenient transportation

(2)Service wide-ranging(high recovery) .Only high recovery will make more sense to build the recycle bin.Two factors,Service wide-ranging and convenient transportation are the most valued to build waste appliance recycle bin.

(3)Smaller cost.Costs include construction cost,operation cost and transport cost,transportation cost of recycle bin,ect.

(4)Shorter distances.It's a best thing if you could establish a waste appliance recycle bin in each suburb.If the deviation is too far to go to the recycle bin inconveniently that will seriously hindered the amount and effectiveness of appliance reclaim nor improve the cost.

(5)Slight environmental pollution.A purpose must be observed when recycling of waste appliance,slight environmental pollution.

3.2System analysis of influence factors about the appliances garbage recycle bin location by AHP

There are numerous factors involved in the appliances garbage recycle bin location. Firstly classify the factors of research problems, and then construct a hierarchical model of mutual coupling between each of the factors.As shown in Figure 1,the first layer is the target layer of $\mathrm{O}$, the second layer is the criterion layer of $\mathrm{A}$ (metric layer target whether be achieved),the third layer is the scheme layer of B.In Figure 1,the target layer is the optimal scheme;Layer criterion as a standard to evaluate the advantages and disadvantages of appliance waste recycle bin site plan,including traffic conditions, service area, the cost, distance, degree of environmental pollution, etc; Plan layer to be selected for the recycling of waste appliances address, at present there are five main alternative address. 


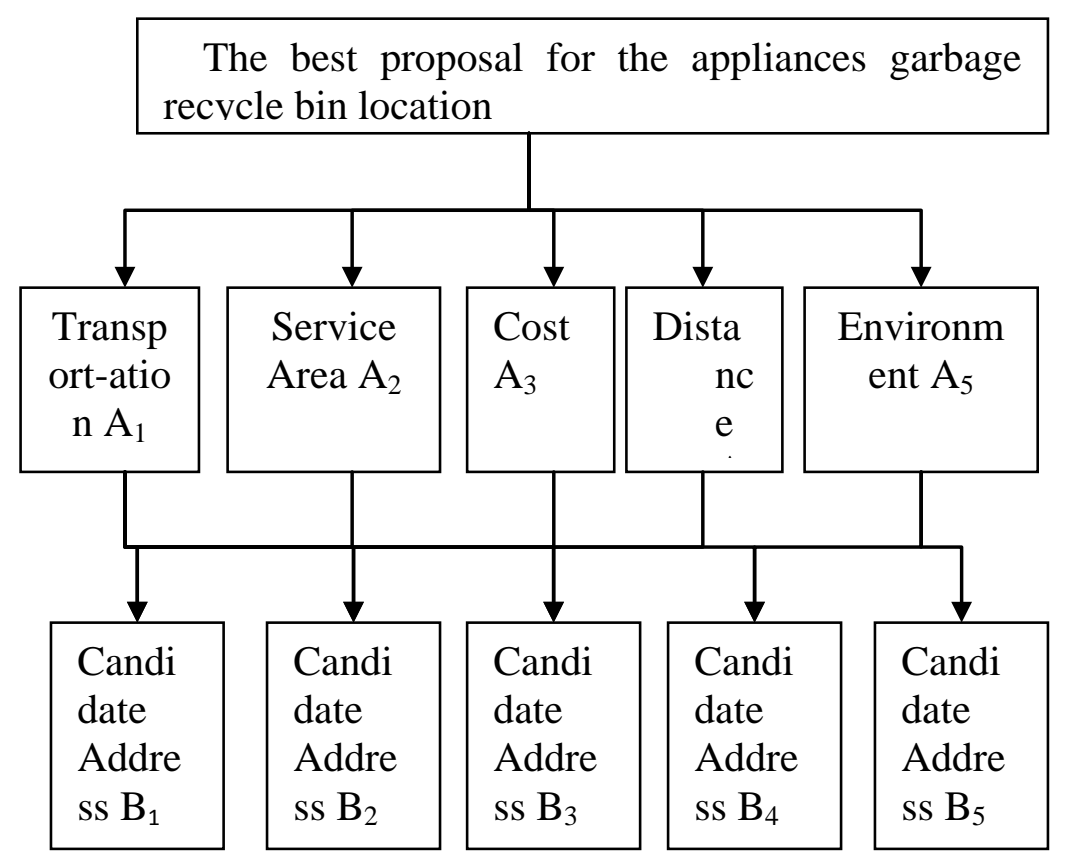

Fig.1. The hierarchy analysis structure graph of recycle bin adress

\section{Construction location model of recycle bin based on AHP}

\subsection{1 Model establishment}

(1) Selecting evaluation index. According to the actual situation of the national related policy and analysis of entity, make the effect of analysis model.

(2)Establishing the hierarchical structure model. The hierarchical structure of the model top layer is the target layer, usually only one factor, most lower level usually scheme or the object layer, the middle one or several levels, usually as the criteria or indicators layer. When there are too many criterions,it should be further decomposed into sub rule layer. The division of each evaluation index is 3 to 4 levels, each with 0.01 to 1 score[4].

(3) Constructing judgment matrix. To determine the proportion of $n$ factors$\mathrm{B}_{1}, \mathrm{~B}_{2}, \mathrm{~B}_{3}, \ldots \mathrm{B}_{\mathrm{n}}$ in $\mathrm{Z}$ which influence the objective $\mathrm{Z}$.Use the paired comparison method and $1 \sim 9$ comparison scale to construct comparison matrix, and use $\mathrm{a}_{\mathrm{ij}}$ to represent the degree of influence $B_{i}$ and $B_{j}$ for $Z$. 
(4)To calculate the weight of each index and do the consistency test. First, Calculate and judge the multiplying of each row elements in the matrix;

$$
\mathrm{M}_{\mathrm{i}}=\prod_{\mathrm{i}=1}^{\mathrm{n}} \mathrm{a}_{\mathrm{ij}} \quad(\mathrm{i}=1,2,3 \cdots \cdots \mathrm{n})
$$

Then, calculate $\mathrm{n}$ root: $\mathrm{W}_{\mathrm{i}}=\mathrm{n}$

Use the sum-product method to calculate eigenvector and maximum eigenvalue- $\lambda_{\max }$ of each judgment matrix that eigenvector is the weight of each index. When $\lambda_{\max } \neq \mathrm{n}$, the consistency index of judgment matrix is:

$$
\mathrm{CI}=\left(\lambda_{\max }-\mathrm{n}\right) /(\mathrm{n}-1)
$$

The consistency index RI of judgment matrix. When the random consistency ratio $\mathrm{CR}=\mathrm{CI} / \mathrm{RI}<0.10$, judgment matrix has the satisfied consistency, or should make appropriate adjustment of judgment matrix.

(5)Calculate the combination vector and check combination consistency. Calculate of the most lower on target, and according to the formula do combined consistency test. If the test passes, it can make decision according to the the result of eigenvector ,otherwise it will need to reconsider the model or construct consistency ratio larger pairwise comparison matrix. The results of comprehensive evaluation represents with comprehensive evaluation index, calculating using the multi-objective linear weighting function method.

\subsection{Analysis of appliances garbage bin location by AHP}

Comprehensively considering the involved factors,adopt the principle of hierarchy analysis and solicit the opinions of the experts, through the investigation and study, combine with the specific circumstances of the candidate recycling bin address, use the method of combining Delphy Fa and AHP method, comprehensively analyse the results of operations shown in Table 2. The $A_{1}, A_{2}$, $A_{3}, A_{4}, A_{5}$ respectively represent traffic conditions, service area, cost, distance, the degree of environmental pollution[5]. 
Table 2 The factor weight

\begin{tabular}{|c|c|c|c|c|c|c|c|c|c|}
\hline $\mathrm{O}$ & $\begin{array}{c}\text { A } \\
1\end{array}$ & 2 & $\begin{array}{l}\text { A } \\
3\end{array}$ & $\begin{array}{l}\text { A } \\
4\end{array}$ & A & $\mathrm{W}_{\mathrm{i}}$ & $\mathrm{W}_{\mathrm{i}}{ }^{0}$ & $\lambda_{\mathrm{mi}}$ & \multirow{6}{*}{ 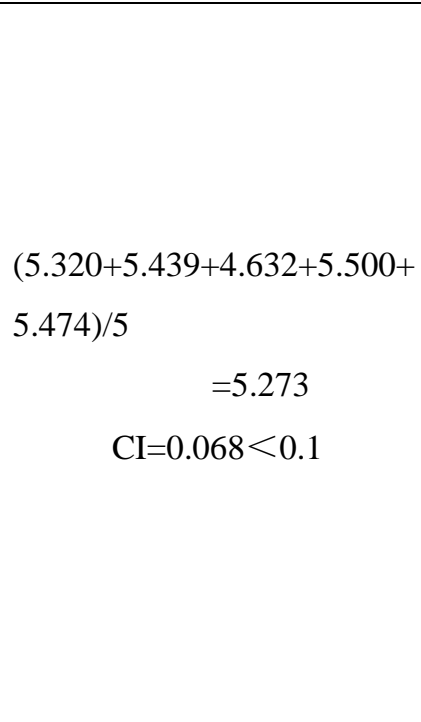 } \\
\hline A & 1 & 5 & 2 & 3 & $1 /$ & $\begin{array}{c}1.71 \\
9\end{array}$ & $\begin{array}{c}0.28 \\
9\end{array}$ & $\begin{array}{c}5.32 \\
0\end{array}$ & \\
\hline A & $\begin{array}{l}1 / \\
5\end{array}$ & 1 & $\begin{array}{l}1 / \\
3\end{array}$ & $\begin{array}{l}1 / \\
5\end{array}$ & 1/ & $\begin{array}{c}0.33 \\
9\end{array}$ & $\begin{array}{c}0.05 \\
7\end{array}$ & $\begin{array}{c}5.43 \\
9\end{array}$ & \\
\hline A & $\begin{array}{l}1 / \\
2\end{array}$ & 3 & 1 & $\begin{array}{l}1 / \\
2\end{array}$ & $1 /$ & $\begin{array}{c}0.82 \\
2\end{array}$ & $\begin{array}{c}0.13 \\
8\end{array}$ & $\begin{array}{c}4.63 \\
2\end{array}$ & \\
\hline$A$ & $\begin{array}{l}1 / \\
3\end{array}$ & 5 & 2 & 1 & $1 /$ & $\begin{array}{c}1.02 \\
1\end{array}$ & $\begin{array}{c}0.17 \\
2\end{array}$ & $\begin{array}{c}5.50 \\
0\end{array}$ & \\
\hline 5 & 2 & 3 & 2 & 3 & 1 & $\begin{array}{c}2.04 \\
8\end{array}$ & $\begin{array}{c}0.34 \\
4\end{array}$ & $\begin{array}{c}5.47 \\
4\end{array}$ & \\
\hline
\end{tabular}

Table 3 The candidate address judgement matrix and the calculation of importance degree and the progress and result of consistency test

\begin{tabular}{|c|c|c|c|c|c|c|}
\hline$A_{1}$ & $\mathrm{~B}_{1}$ & $\mathrm{~B}_{2}$ & $\mathrm{~W}_{\mathrm{i}}$ & $\mathrm{W}_{\mathrm{i}}^{0}$ & $\lambda_{\text {mi }}$ & 2.001 \\
\hline $\mathrm{B}_{1}$ & 1 & 3 & 1.732 & 0.750 & 2.000 & $\mathrm{CI}=0.001<$ \\
\hline $\mathrm{B}_{2}$ & $1 / 3$ & 1 & 0.577 & 0.250 & 2.001 & 0.1 \\
\hline
\end{tabular}

\begin{tabular}{|c|c|c|c|c|c|c|c|}
\hline$A_{2}$ & $\mathrm{~B}_{1}$ & $B_{2}$ & $B_{3}$ & $\mathrm{Wi}$ & $\mathrm{W}_{\mathrm{i}}^{0}$ & $\lambda_{\text {mi }}$ & \multirow{4}{*}{$\begin{array}{c}\mathrm{CI}=0.034< \\
0.1\end{array}$} \\
\hline $\mathrm{B}_{1}$ & 1 & $1 / 5$ & $1 / 3$ & 0.405 & 0.105 & 3.128 & \\
\hline $\mathrm{B}_{2}$ & 5 & 1 & 3 & 2.466 & 0.637 & 3.038 & \\
\hline $\mathrm{B}_{3}$ & 3 & $1 / 3$ & 1 & 1.000 & 0.258 & 3.037 & \\
\hline
\end{tabular}

\begin{tabular}{|c|c|c|c|c|c|c|c|}
\hline$A_{3}$ & $\mathrm{~B}_{3}$ & $\mathrm{~B}_{4}$ & $\mathrm{~B}_{5}$ & $\mathrm{Wi}$ & $\mathrm{W}_{\mathrm{i}}^{0}$ & $\lambda_{\mathrm{mi}}$ & \multirow{4}{*}{$\begin{array}{c}3.108 \\
\mathrm{CI}=0.054< \\
0.1\end{array}$} \\
\hline $\mathrm{B}_{3}$ & 1 & 3 & 2 & 1.817 & 0.517 & 3.108 & \\
\hline $\mathrm{B}_{4}$ & $1 / 3$ & 1 & $1 / 4$ & 0.437 & 0.124 & 3.107 & \\
\hline $\mathrm{B}_{5}$ & $1 / 2$ & 4 & 1 & 1.260 & 0.359 & 3.108 & \\
\hline
\end{tabular}




\begin{tabular}{|c|c|c|c|c|c|c|c|c|}
\hline $\mathrm{A}_{4}$ & $\mathrm{~B}_{1}$ & $\mathrm{~B}_{2}$ & $\mathrm{~B}_{3}$ & $\mathrm{~B}_{5}$ & Wi & $\mathrm{W}_{\mathrm{i}}^{0}$ & $\lambda_{\mathrm{mi}}$ & \multirow{5}{*}{$\begin{array}{c}4.222 \\
\mathrm{CI}=0.074< \\
0.1\end{array}$} \\
\hline $\mathrm{B}_{1}$ & 1 & $1 / 3$ & $1 / 5$ & 1 & 0.508 & 0.100 & 4.288 & \\
\hline $\mathrm{B}_{2}$ & 3 & 1 & 3 & 5 & 2.590 & 0.507 & 4.301 & \\
\hline $\mathrm{B}_{3}$ & 5 & $1 / 3$ & 1 & 3 & 1.495 & 0.293 & 4.296 & \\
\hline $\mathrm{B}_{5}$ & 1 & $1 / 5$ & $1 / 3$ & 1 & 0.508 & 0.100 & 4.001 & \\
\hline
\end{tabular}

\begin{tabular}{|c|c|c|c|c|c|c|c|}
\hline $\mathrm{A}_{5}$ & $\mathrm{~B}_{1}$ & $\mathrm{~B}_{4}$ & $B_{5}$ & Wi & $\mathrm{W}_{\mathrm{i}}^{0}$ & $\lambda_{\text {mi }}$ & \multirow{4}{*}{$\begin{array}{c}3.136 \\
\mathrm{CI}=0.068< \\
0.1\end{array}$} \\
\hline $\mathrm{B}_{1}$ & 1 & 3 & $1 / 5$ & 0.843 & 0.202 & 3.135 & \\
\hline $\mathrm{B}_{4}$ & $1 / 3$ & 1 & $1 / 5$ & 0.405 & 0.097 & 3.138 & \\
\hline$B_{5}$ & 5 & 5 & 1 & 2.924 & 0.701 & 3.134 & \\
\hline
\end{tabular}

The total sequencing result of B layer as shown in table 4 .

Table 4 The total sequencing of $B$ layer

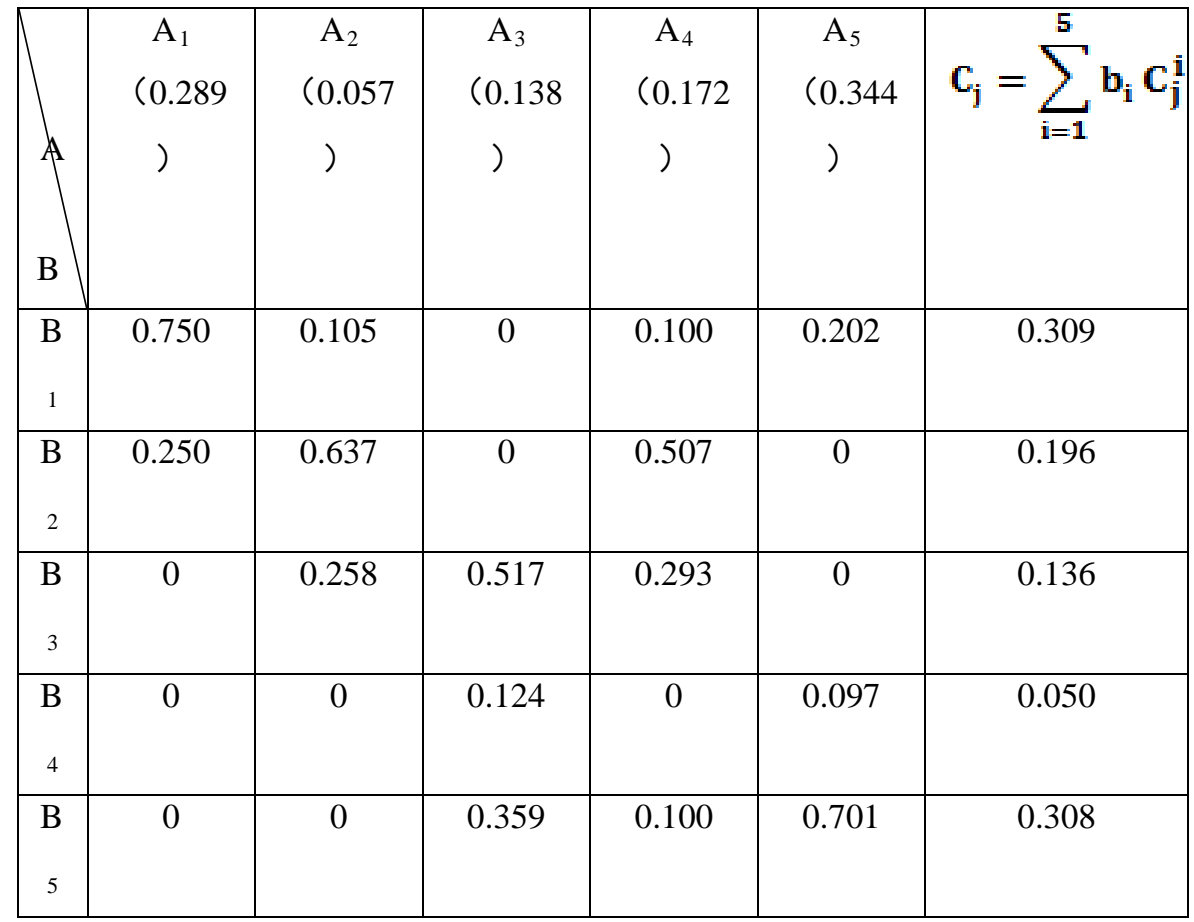

The results showed that the merits of the order of five programs:

$\mathrm{B}_{1}, \mathrm{~B}_{5}, \mathrm{~B}_{2}, \mathrm{~B}_{3}, \mathrm{~B}_{4}$, and the program $\mathrm{B}_{1} \cdot \mathrm{B}_{5}$ was significantly superior to Scheme 
$B_{2}, B_{3}$ and $B_{4}$. That appliances garbage recycle bin selects $B_{1}$ and $B_{5}$ position is reasonable.

\section{Conclusion}

The process of appliances garbage recycle bin involved more factors.Based on the analysis of appliances garbage recycle bin,use construct and solve the recycle bin location problem.And verify AHP model levels to illustrate a more scientific and reasonable recycling location model so that it can relize high recovery of appliances waste, less pollution to the environment, and also higher profits.

\section{References}

[1] Shi Zhenyuan, Yang Shuhan. Beijing household appliances reverse logistics

[J]. Chinese securities and futures, 2010, tenth period.

[2] Bian Yiwen, Sun Xiangyang, Li Shangyu. [J]. industrial engineering and management, electronic wastes recycling point location based on DEA in 2012 October, the seventeenth volume fifth issue.

[3] He Bo, Yang Chao, Zhang Hua. The waste recycling multilayer reverse logistics network optimization design of [J]. China management science, 2007, 15 (3): 61-67

[4] Wang Yingluo. Systems engineering [M]. Beijing: Mechanical Industry Press, 2003

[5] Zhang Feng,. Oil distribution center AHP - integer programming method based on the [J]. location model of logistics engineering and management, 2010, 32 (1):2-4. 